\title{
A game theory model for pricing and supplier selection in a closed-loop supply chain
}

\author{
Maryam Esmaeili*, Somayeh Najafi Ghobadi \\ Department of Industrial Engineering, Alzahra University,Tehran, Iran \\ ®esmaeili_m@alzahra.ac.ir
}

\begin{abstract}
In this paper, pricing and supplier selection in a closed-loop supply chain (CLSC) are modelled by a game theory approach. The CLSC includes one manufacturer and multi-suppliers. The manufacturer collects the used products where the number of defective parts purchased from the suppliers is random variable. The suppliers determine standard deviation and the wholesale price. For the defective parts greater than the expected number, the manufacturer penalises the suppliers. The manufacturer determines the optimal selling price, the price of collecting a used product, appropriate suppliers, and the penalty cost by maximising the profit. The end demand is affected by the selling price, and the competition between the suppliers is considered based on the Bertrand model. The interaction between the manufacturer and the suppliers is modelled by the static and dynamic games to obtain Nash and Stackelberg equilibriums. Finally, the numerical examples and sensitivity analysis are presented to illustrate the theoretical results.
\end{abstract}

Keywords: closed-loop supply chain; CLSC; supplier selection; pricing; game theory; defective parts; static game; dynamic game; Bertrand model; penalty cost.

Link: https://www.inderscience.com/info/inarticle.php?artid=92771 